
IP Periodica Polytechnica
Civil Engineering

61 (4), pp. 920-928, 2017

https://doi.org/10.3311/PPci.10022

Creative Commons Attribution (i)

RESEARCH ARTICLE

\section{Examination of Autonomous GPS and GPS/EGNOS Integrity and Accuracy for Aeronautical Applications}

\author{
Adam Ciećko ${ }^{1, *}$, Grzegorz Grunwald ${ }^{1}$
}

Received 14 September 2016; Revised 01 March 2017; Accepted 03 April 2017

\begin{abstract}
The Global Navigation Satellite System (GNSS) is increasingly used in navigation and positioning in land, water and air applications. Although they are very useful and willingly employed in everyday live and commercial products, it must be stressed that GNSS alone does not always provide adequate performance, particularly in demanding aeronautical applications where high level of integrity is required. Integrity and accuracy of positioning are the key parameters in air navigation.

The paper presents research on current values of GNSS accuracy and integrity in north-eastern Poland, the region which until 2014 was out of official coverage of European Geostationary Navigation Overlay Service (EGNOS) Open Service (OS). The integrity and accuracy of positioning of static point and flying aircraft was examined in order to check present usability of different GNSS techniques which can be deployed for enroute, approach and landing phase of a flight. Since the integrity levels in aviation are strictly dependent on the phase of flight and landing of an aircraft, the analyses were performed in two computational modes: positioning using GPS/EGNOS data and using autonomous GPS. Both modes were calculated in en-route variant and because with the use of EGNOS it is possible to perform approach, GPS/EGNOS mode was also analyzed in Precision Approach (PA) variant. Overall assessment of the accuracy and integrity of positioning in the studied variants is at the satisfactory level, not exceeding the levels defined by official aviation regulations.
\end{abstract}

Keywords

GNSS navigation, SBAS, EGNOS, integrity

\section{Introduction}

Navigation of an aircraft is one of the crucial aspects in air transport. In order to achieve high level of safety it must be accurate and reliable. Nowadays GNSS offers new standards and possibilities for air navigation which can overcome many disadvantages of classical navigation systems. On the other hand, in order to use GNSS as the primary source for navigation in aviation, stringent requirements have to be met. GNSS use in safety-critical applications makes integrity mandatory: the timely provision of information to users about the level of trustworthiness of a position solution by defining the maximum deviation from the true position with a certain amount of probability [1], including the ability of providing alerts to the user when the requirements are not assured to be met. The American GPS system architecture incorporates many features including redundant hardware, robust software, and rigorous operator training to minimize integrity anomalies, however resolution of an unanticipated satellite integrity anomaly may take up to 6 hours. Even the best response time may be on the order of several minutes, which is insufficient for safety of life (SoL) applications [2]. For such applications, augmentations of GPS such as Aircraft Based Augmentation Systems (ABAS), Space Based Augmentation Systems (SBAS) or Ground Based Augmentation Systems (GBAS) must be applied to achieve the requisite level of integrity. ABAS, SBAS and GBAS provide integrity in a multi-step procedure that is laid out in the Radio Technical Commission for Aeronautics (RTCA) Minimum Operational Performance Standards (MOPS) for airborne navigation equipment using: GPS not augmented by ground- or space-based systems - DO-316 [3], GPS augmented by SBAS - DO-229D [4] and GPS augmented by GBAS - DO-253C [5].

The most promising results today are offered by SBAS systems which provide valuable and cost effective information for air community. The SBAS system used in Europe is called EGNOS, another operational today systems include the American Wide Area Augmentation System (WAAS), the Japanese MTSAT Satellite Augmentation System (MSAS) and the Indian GPS-Aided GEO Augmented and Navigation System (GAGAN) [6].
${ }^{1}$ Department of Satellite Geodesy and Navigation,

Faculty of Geodesy, Geospatial and Civil Engineering,

University of Warmia and Mazury in Olsztyn,

ul. Oczapowskiego 2, 10-719 Olsztyn, Poland

*Correspondent author email: a.ciecko@uwm.edu.pl 


\section{GNSS integrity in aviation}

Integrity is the measure of the trust that can be placed in the correctness of the information supplied by a navigation system. Integrity includes also the ability of the system to provide timely warnings to users when the system should not be used for the intended operation or phase of flight [2]. The concept of GNSS integrity has been originally defined in the civil aviation framework as part of ICAO specifications required to use GNSS in the Communications, Navigation, and Surveillance/ Air Traffic Management (CNS/ATM) system [7, 8]. Integrity requirements consist of four terms [9]:

- Alert limit: The alert limit (xAL) for a given parameter measurement ( $\mathrm{x}$ designating the horizontal $-\mathrm{H}$ or vertical $-\mathrm{V}$ component) is the error tolerance not to be exceeded without issuing an alert.

- Time to alert: Time to alert (TTA) is the maximum allowable elapsed time from the detection of a positioning failure until the equipment annunciates the alert.

- Integrity risk: The integrity risk is the probability of providing a position that is out of tolerance without warning the user within the specified time to alert that results in hazardously misleading information (HMI).

- Protection level: The protection level (xPL), where x designating the horizontal - $\mathrm{H}$ or vertical - $\mathrm{V}$ component, is statistical bound error computed so as to guarantee that the probability of the absolute position error exceeding said number is smaller than or equal to the target integrity risk.

The values of integrity and other fundamental navigation parameters in aviation are highly dependent on the phase of flight, typical ICAO requirements for which are included in Table 1.

Since standalone GPS does not meet the ICAO requirements, different augmentation systems have been developed to fulfill them. In particular, all augmentation systems provide GNSS integrity services. Consequently, most of the integrity monitoring systems, techniques and algorithms have been designed to support civil aviation operations within the ICAO specifications.

The basic form of augmentation is ABAS, which does not require additional ground or satellite infrastructure of the integrity system, but algorithms. The most common ABAS technique is called receiver autonomous integrity monitoring (RAIM), which can be used if there are more than four satellites with suitable geometry available. With five satellites in view, five independent positions can be computed. If these do not match, it can be deduced that one or more of the satellites are giving incorrect information. If there are six or more satellites in view, more independent positions can be calculated and a receiver may then be able to identify one faulty satellite and exclude it from the position determination calculations [7]. The requirement for redundant signals means that navigation guidance with integrity provided by RAIM may not be available 100 per cent of the time. RAIM availability depends also on the type of operation and currently it does not provide integrity for any approach requiring vertical guidance, which means it can only be used for non-precision approach (NPA) and operation like en-route or terminal.

A key issue related to RAIM algorithms is that one of the objectives of their actions is to find measurement errors resulting from emergency situations which are very rare, with a typical rate of one error per 18 to 24 months in the GPS system. Due to the rarity of these errors, it is usually assumed that only one satellite may malfunction, or the probability of occurrence of a number of "defective" satellites is negligible [10]. Most of the RAIM algorithms work as follows:

- Computation of navigation solution,

- Detection of faults and anomalies,

- Isolation of faulty satellites,

- Determination of the protection levels (PL).

Table 1 Performance requirements for different phases of flight and landing of a civil aircraft [8]

\begin{tabular}{|c|c|c|c|c|c|c|c|}
\hline \multirow{3}{*}{$\begin{array}{l}\text { Aircraft Phase } \\
\text { of Flight }\end{array}$} & \multirow{2}{*}{\multicolumn{2}{|c|}{$\frac{\text { Accuracy }}{(2 \sigma \text { or } 95 \%)}$}} & \multicolumn{3}{|c|}{ Integrity } & \multicolumn{2}{|c|}{ Maximum Probabilities of Failure } \\
\hline & & & \multicolumn{2}{|c|}{ Alert Limits (4-6 $\sigma)$} & \multirow{2}{*}{$\begin{array}{l}\text { Time to } \\
\text { Alert }\end{array}$} & \multirow{2}{*}{ Integrity } & \multirow{2}{*}{ Continuity } \\
\hline & Vertical & Horizontal & Vertical & Horizontal & & & \\
\hline En-route, Terminal & N/A & $0.74-3.7 \mathrm{~km}$ & $\mathrm{~N} / \mathrm{A}$ & $1.85-7.4 \mathrm{~km}$ & $5 \mathrm{~min}-15 \mathrm{~s}$ & $10^{-7} / \mathrm{hr}$ & $10^{-4} / \mathrm{hr}$ \\
\hline $\begin{array}{l}\text { NPA, Initial Ap- } \\
\text { proach, Departure }\end{array}$ & N/A & $0.22-0.74 \mathrm{~km}$ & N/A & $\begin{array}{c}1.85-3.7 \\
\mathrm{~km}\end{array}$ & $10-15 \mathrm{~s}$ & $10^{-7} / \mathrm{hr}$ & $10^{-4} / \mathrm{hr}$ \\
\hline LNAV/VNAV & \multirow{3}{*}{$20 \mathrm{~m}$} & $220 \mathrm{~m}$ & \multirow{2}{*}{$50 \mathrm{~m}$} & $556 \mathrm{~m}$ & \multirow{3}{*}{$10 \mathrm{~s}$} & \multirow{6}{*}{$\begin{array}{c}1-2 \times 10^{-7 /} \\
150 \mathrm{~s}\end{array}$} & \multirow{6}{*}{$\begin{array}{c}4-8 \times 10^{-6} \% \\
15 \mathrm{~s}\end{array}$} \\
\hline LPV & & \multirow{5}{*}{$16 \mathrm{~m}$} & & \multirow{5}{*}{$40 \mathrm{~m}$} & & & \\
\hline APV-I & & & $35 \mathrm{~m}$ & & & & \\
\hline APV-II & $8 \mathrm{~m}$ & & $20 \mathrm{~m}$ & & \multirow{3}{*}{$6 s$} & & \\
\hline LPV 200 & \multirow[b]{2}{*}{$4 \mathrm{~m}$} & & $35 \mathrm{~m}$ & & & & \\
\hline $\begin{array}{l}\text { Precision Approach } \\
\text { CAT I }\end{array}$ & & & $10 \mathrm{~m}$ & & & & \\
\hline $\begin{array}{l}\text { Precision Approach } \\
\text { CAT II/III }\end{array}$ & $<2.9 \mathrm{~m}$ & $<6.9 \mathrm{~m}$ & $5.3 \mathrm{~m}$ & $<17 \mathrm{~m}$ & $<2 \mathrm{~s}$ & $\begin{array}{l}<10^{-9} / \\
150 \mathrm{~s}\end{array}$ & $\begin{array}{c}<4 \times 10^{-6} \% \\
15 \mathrm{~s}\end{array}$ \\
\hline
\end{tabular}


Another, currently the most popular form of augmentation in aviation is SBAS, which allows for approach procedures with vertical guidance (APV). A key to providing APV approaches with SBAS is correcting for the signal delay caused by the ionosphere. This requires a relatively dense network of reference stations and complex calculations to ensure the integrity of these corrections [11]. European EGNOS operates in common international standard and currently complements the GPS system, by broadcasting on the GPS L1 frequency integrity messages in real-time and providing information on the health of the GPS constellation. In addition, correction data improves the accuracy of the current GPS services from about $10 \mathrm{~m}$ to about $2 \mathrm{~m}$ in the horizontal dimension. The data produced and transmitted by EGNOS thus include estimates of GPS satellite orbit and clock errors and estimates of errors due to GPS signals crossing the ionosphere. These parameters enable users to evaluate a limit from its position error. All message types transmitted by the system are internationally standardized. For each message type transmitted, there is thus a maximum refresh period which must be taken into account by the system transmitting the signal. A validity period is also defined; it must be applied by the user and can depend on the application. These intervals and periods of EGNOS messages are given in Table 2 [12].

Table 2 The structure of messages transmitted by EGNOS system [12]

\begin{tabular}{|c|c|c|c|c|}
\hline \multirow[b]{2}{*}{ Types } & \multirow[b]{2}{*}{ Data contained } & \multirow{2}{*}{$\begin{array}{c}\text { Refresh } \\
\text { period } \\
\text { (s) }\end{array}$} & \multicolumn{2}{|c|}{ Validity period (s) } \\
\hline & & & $\begin{array}{c}\text { En-route, } \\
\text { Terminal, } \\
\text { NPA }\end{array}$ & PA, APV \\
\hline 0 & $\begin{array}{l}\text { Don't use for safety ap- } \\
\text { plications }\end{array}$ & 6 & $60 *$ & $60 *$ \\
\hline 1 & PRN mask & $120 * *$ & 600 & 600 \\
\hline 2 to 6,24 & $\begin{array}{l}\text { UDRE (User Differen- } \\
\text { tial Range Error) }\end{array}$ & 6 & 18 & 12 \\
\hline 2 to 5,24 & Fast Corrections & Variable** & Variable** & Variable** \\
\hline 24,25 & Long Term Corrections & 120 & 360 & 240 \\
\hline 9 & GEO Navigation Data & 120 & 360 & 240 \\
\hline 7 & $\begin{array}{l}\text { Fast Correction Degra- } \\
\text { dation }\end{array}$ & 120 & 360 & 240 \\
\hline 10 & Degradation Parameters & 120 & 360 & 240 \\
\hline 18 & Ionospheric Grid Mask & $300 * * *$ & 1200 & 1200 \\
\hline 26 & Ionospheric Corrections & 300 & 600 & 600 \\
\hline 12 & UTC Timing Data & 300 & 86400 & 86400 \\
\hline 17 & Almanac Data & 300 & None & None \\
\hline 27 & Service Level & $\begin{array}{c}300 \\
\text { (if used) }\end{array}$ & 86400 & 86400 \\
\hline
\end{tabular}

(*) Message type 0 must be sent only if the system is not usable for safety-critical applications. After the reception of a message type 0 the SBAS signal shall be de-selected and all data received for one minute shall be discarded.

(**) The value depends on the degradation factor for the fast corrections.

(***) When the masks are modified, message type 1 or 18 must be repeated several times before the new mask can be used. This ensures that all users have received the new mask before it is applied.

\section{Determining of the protection level}

Since the values of protection levels in aviation are strictly dependent on the phase of flight and landing of civil aircraft (see Table 1), the analyses were performed in two computational modes: positioning using GPS/EGNOS data (for APV-1 operations) and using autonomous GPS (for en-route operations). In case of GPS/EGNOS mode pseudoranges from EGNOS geostationary satellites were excluded from the solution.

Integrity in GNSS positioning augmented by SBAS systems is dependent on the geometry of the satellites, the impact of the ionosphere, troposphere, ephemeris errors, delays of GNSS satellites clocks and errors associated with the operation of the receiver itself [4]. During the research, the model used for determining the value of HPL and VPL was strictly in accordance with the RTCA [4] guidelines. PL values are calculated using formulas $[4,13]$ :

$$
\begin{gathered}
H P L=K_{H} d_{\text {major }} \\
V P L=K_{V} \sigma_{U}
\end{gathered}
$$

where:

$K_{H}$ - a factor bounding user's horizontal position with a probability of $10^{-9}$ (for en-route navigation $K_{H}=6.18$ and for precision approach $K_{H}=6.0$ ),

$K_{V}$ - a factor bounding the user's vertical position with a probability of $0.5 \times 10^{-7}(=5.33)$.

$$
\begin{gathered}
d_{\text {major }}=\sqrt{\frac{d_{E}^{2}+d_{N}^{2}}{2}+\sqrt{\left(\frac{d_{E}^{2}-d_{N}^{2}}{2}\right)^{2}+d_{E N}^{2}}} \\
d_{E}^{2}=\sum_{i=1}^{n} S_{E, i}^{2} \sigma_{i}^{2}, \quad d_{N}^{2}=\sum_{i=1}^{n} S_{N, i}^{2} \sigma_{i}^{2}, \\
d_{E N}=\sum_{i=1}^{n} S_{E, i} S_{N, i} \sigma_{i}^{2}, \quad d_{U}^{2}=\sum_{i=1}^{n} S_{U, i}^{2} \sigma_{i}^{2} \\
\boldsymbol{S}=\left[\begin{array}{llll}
S_{E, 1} & S_{E, 2} & \ldots & S_{E, n} \\
S_{N, 1} & S_{N, 2} & \ldots & S_{N, n} \\
S_{U, 1} & S_{U, 2} & \ldots & S_{U, n} \\
S_{t, 1} & S_{t, 2} & \ldots & S_{t, n}
\end{array}\right]
\end{gathered}
$$

where:

$S$ - projection matrix,

$d_{E}^{2}, d_{N}^{2}, d_{U}^{2}$ - variances of the model distribution that overbounds the true error distribution in the East, North and Up (vertical) axis,

$d_{E N}-$ covariance of the model distribution in the East and North axis,

$S_{E, i}$ - the partial derivative of position error in the East direction with respect to the pseudorange error on the $i^{\text {th }}$ satellite,

$S_{N, i}$ - the partial derivative of position error in the North direction with respect to the pseudorange error on the $i^{\text {th }}$ satellite, 
$S_{U, i}$ - the partial derivative of position error in the Up (vertical) direction with respect to the pseudorange error on the $i^{\text {th }}$ satellite,

Variance of measured pseudorange for positioning using SBAS systems can be determined according to RTCA [4] by:

$$
\sigma_{i}^{2}=\sigma_{i, f t t}^{2}+\sigma_{i, \text { UIRE }}^{2}+\sigma_{i, \text { air }}^{2}+\sigma_{i, \text { rropo }}^{2}
$$

where:

$\sigma_{i}^{2}$ - full variance of the pseudorange measurement,

$\sigma_{i, f t}^{2}-$ variance of the residual error after application of fast and slow corrections,

$\sigma_{i, \text { UIRE }}^{2}$ - variance of the residual error after application of ionospheric correction,

$\sigma_{i, a i r}^{2}$ - variance of the contribution of the receiver to the residual error,

$\sigma_{i, t \text { tropo }}^{2}$ - variance of the residual error after application of tropospheric correction.

When the degradation model is offline or data about it are not available, the variance of fast and slow corrections is determined on the basis of the following formula:

$$
\sigma_{i, f t}^{2}=\left[\left(\sigma_{i, U D R E}\right) \cdot\left(\delta_{U D R E}\right)+8 m\right]^{2}
$$

where:

$\sigma_{i, U D R E}$ - standard deviation of UDRE (transmitted by SBAS system). If the value $\delta_{U D R E}$ is not transmitted by the system, it assumes a value equal to 1 .

When using the degradation model of fast and slow corrections the value of $\sigma_{i, f t}^{2}$ is calculated from the formula:

$$
\begin{aligned}
& \sigma_{i, f f t}^{2}=\left[\left(\sigma_{i, U D R E}\right) \cdot\left(\delta_{U D R E}\right)+\varepsilon_{f c}+\varepsilon_{r r c}+\varepsilon_{l t c}+\varepsilon_{e r}\right]^{2}, \\
& \text { if } \operatorname{RSS}_{U D R E}=0 \\
& \sigma_{i, f t t}^{2}=\left[\left(\sigma_{i, U D R E}\right) \cdot\left(\delta_{U D R E}\right)\right]^{2}+\varepsilon_{f c}{ }^{2}+\varepsilon_{r r c}{ }^{2}+\varepsilon_{l t c}{ }^{2}+\varepsilon_{e r}{ }^{2}, \\
& \text { if } \operatorname{RSS}_{U D R E}=1
\end{aligned}
$$

wherein:

$R S S_{\text {UDRE }}$ - root sum square flag of UDRE (transmitted by SBAS system),

$\varepsilon_{f c}-$ degradation parameter for fast correction data,

$\varepsilon_{r r c}$ - degradation parameter for range rate correction data,

$\varepsilon_{l t c}$ - degradation parameter for long term correction data or GEO navigation message data,

$\varepsilon_{e r}-$ degradation parameter for en-route through NPA applications.

The variance of ionospheric delay is calculated according to the following formula:

$$
\begin{gathered}
\sigma_{i, \text { UIRE }}^{2}=F_{P P}^{2} \sigma_{i, \text { UIVE }}^{2} \\
\sigma_{i, \text { UIVE }}^{2}=\sum_{n=1}^{4} W_{n}\left(x_{P P}, y_{P P}\right) \sigma_{n, \text { ionogrid }}^{2} \\
\sigma_{n, \text { ionogrid }}^{2}=\sigma_{G I V E}^{2}+\sigma_{\text {iono }}^{2}
\end{gathered}
$$

where:

$F_{P P}-$ obliquity factor that transforms vertical delay to slant,

$W_{n}$ - weighting function,

$\sigma_{n, \text { ionogrid }}^{n}-$ grid ionospheric vertical error bound with degradation over time,

$x_{P P}, y_{P P}-$ coordinates of interpolation grid points,

$\sigma_{G I V E}^{2}$ - grid ionospheric vertical error bound,

$\sigma_{\text {iono }}^{2}$ - degradation of ionospheric correction information.

For the I class receivers: $\sigma_{i, a i r}^{2}=25 \mathrm{~m}^{2}$.

However, for the receivers of classes II, III and IV the variance of the errors associated with the operation of the GNSS receiver may be determined using following formula:

$$
\sigma_{i, \text { air }}^{2}=\sigma_{i, \text { noise }}^{2}+\sigma_{i, \text { multipath }}^{2}+\sigma_{i, \text { divg }}^{2}
$$

where:

$\sigma_{i, \text { noise }}^{2}$ - variance mainly related to receiver noise and thermal noise,

$\sigma_{i, \text { multipath }}^{2}$ - variance related to multipath,

$\sigma_{i, \text { divg }}^{2}$ - variance related to code pseudorange smoothing.

The variance of tropospheric delay can be determined from the formula:

$$
\sigma_{i, t r o p o}^{2}=\left(\sigma_{T V E} \cdot m\left(E l_{i}\right)\right)^{2}
$$

where:

$\sigma_{T V E}$ - tropospheric vertical error $(0.12 \mathrm{~m})$, $m\left(E l_{i}\right)$ - mapping function for satellite elevation.

In contrast, the variance of the pseudorange measurement for autonomous GPS positioning can be determined by [3]:

$$
\sigma_{i}^{2}=U R A_{i}^{2}+\sigma_{i, \text { UIRE }}^{2}+\sigma_{i, a i r}^{2}+\sigma_{i, \text { tropo }}^{2}
$$

$U R A_{i}^{2}$ - variance of satellite clock and ephemeris errors,

$\sigma_{i, \text { UIRE }}^{2}$ - variance of the residual error after application of ionospheric correction,

$\sigma_{i, a i r}^{2}-$ variance of the contribution of the receiver to the residual error,

$\sigma_{i, t r o p o}^{2}-$ variance of the residual error after application of tropospheric correction.

The variance of ionospheric delay can be determined based on the formula:

$$
\sigma_{i, \text { UIRE }}^{2}=\max \left(\left(\frac{T_{\text {iono }}}{5}\right)^{2},\left(F_{P P} \tau_{\text {vert }}\right)^{2}\right)
$$

where:

$T_{\text {iono }}$ - ionospheric corrections of Klobuchar error model,

$F_{P P}$ - obliquity factor that transforms vertical delay to slant,

$$
\tau_{\text {vert }}=\left\{\begin{array}{ll}
9 m, & 0 \leq\left|\Phi_{m}\right| \leq 20 \\
4.5, & 20<\left|\Phi_{m}\right| \leq 55 \\
6, & 55<\left|\Phi_{m}\right|
\end{array}\right\}
$$

$\Phi_{m}-$ geomagnetic latitude of ionospheric pierce point (in degrees). 
For the receivers not using smoothing of the code observations with phase $\sigma_{i \text {,air }}^{2}=25 \mathrm{~m}^{2}$

Variance of tropospheric delay can be designated on the basis of formula (14).

\section{Flight test}

To use SBAS in aviation, not only the system must be operational but also the system validation in particular localization is needed, as well as official flight procedure design and certification. The research on the quality of the EGNOS in Poland carried out in recent years has shown that a lack of Ranging and Integrity Monitoring Stations (RIMS) east of Warsaw impairs the quality of the system, especially in eastern Poland, where Differential Global Positioning System (DGPS) was commonly used instead [14, 15]. However, in 2014 a new official document based on EGNOS upgrade programme, was published by the European Commission's Directorate-General for Enterprise and Industry showing that the declared area of EGNOS OS coverage was greatly expanded east of the RIMS station located in Warsaw [16]. Performed experiment and detailed analyses aim to present possible to obtain results of GPS and GPS/EGNOS positioning in air traffic in north-eastern Poland after implementation of new algorithms in EGNOS system.

The practical tests were conducted on August 29, 2014 with the use of Diamond DA20-C1 airplane. GNSS receiver taking part in the experiment - Septentrio AsteRx2 - was placed in the cabin of the plane while an external antenna was installed on the top of the cockpit in an almost obstruction free place (Figure 1). The analyzed data were recorded between 12:06 and 13:27 (GPS time), during which the plane passed the route including Olsztyn - Tomaszkowo - Stawiguda - Pluski - Olsztyn (Figure 2). It should be noted that the model of the receiver used in the study, despite the fact that it is widely used in the analysis of EGNOS system, does not have officially required aviation certificates. Also, the antenna mounted in the cockpit of the aircraft, is not a dedicated external aviation antenna. In addition, the second Septentrio AsteRx2 receiver working as a static permanent EGNOS monitoring station at the airport Olsztyn-Dajtki EPOD was used in the experiment as a reference. The station was connected to a choke-ring antenna mounted on a specially adapted mast in the location that had been previously tested for the presence of potential interference of the GNSS signal with signals generated by the communication equipment installed at the airport. During the test both receivers recorded GPS and EGNOS data with an interval of 1 second.

In the first step of computation a true (reference) trajectory of the airplane for each second of the flight was established. For this reason, a Trimble Business Centre (TBC) Software was used allowing to get accuracy of 3D airplane positioning in the range of few centimeters. Following calculations were made with the use of Septentrio Post Processing SDK software and a specialist PP_SBAS_Analyzer software developed by the authors. The self-developed application was used to perform data filtering, to determine the quality parameters of EGNOS system operation and to visualize the results of the experiments. It was designed to make any calculations strictly in accordance with the applicable official aviation documentation. Analyses were performed in two computational modes: positioning using GPS/EGNOS data and using autonomous GPS. Both modes were calculated in "en-route" variant and since with the use of EGNOS it is eligible to perform approach, GPS/EGNOS mode was also analyzed in Precision Approach (PA) variant.

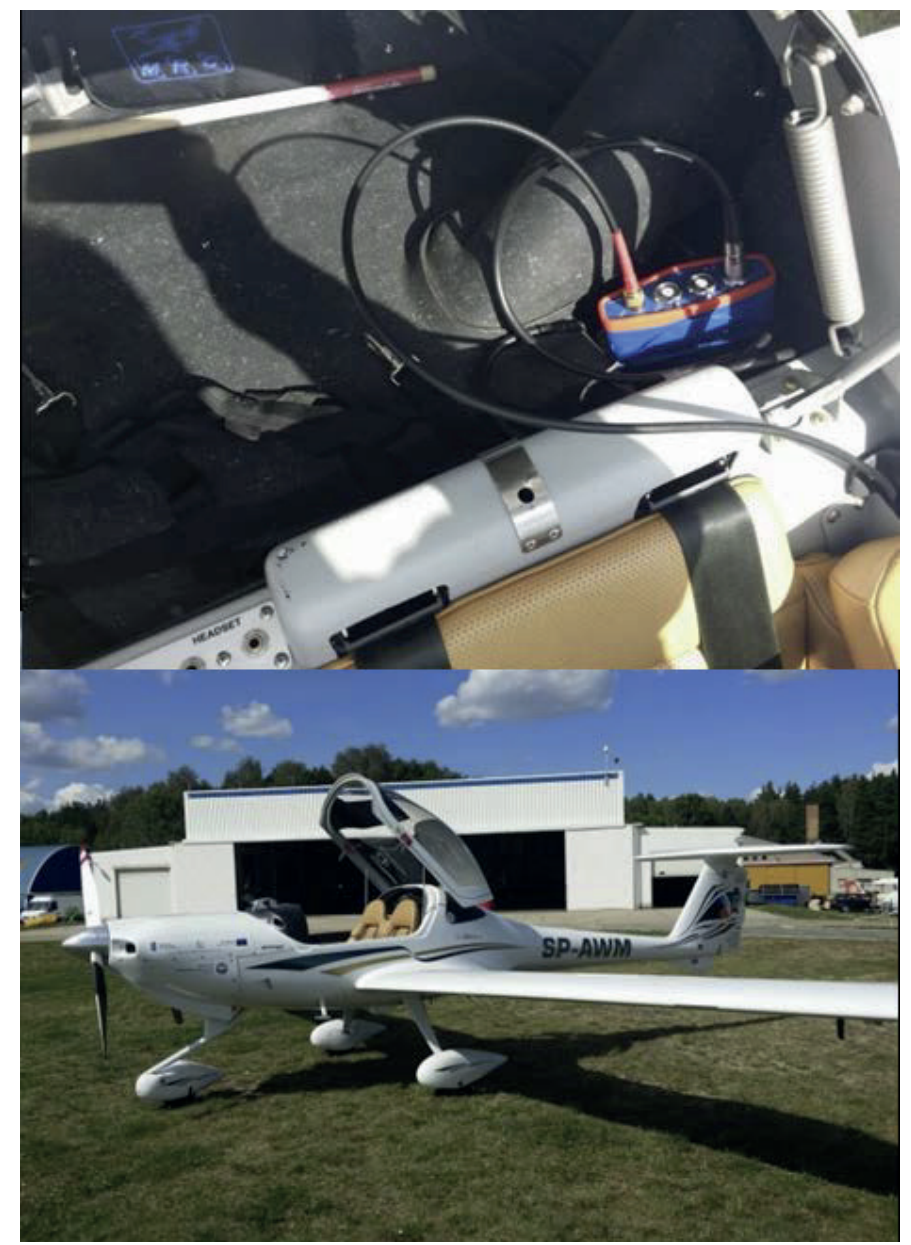

Fig. 1 The Diamond DA 20-C1 plane and measuring equipment involved in the kinematic test 


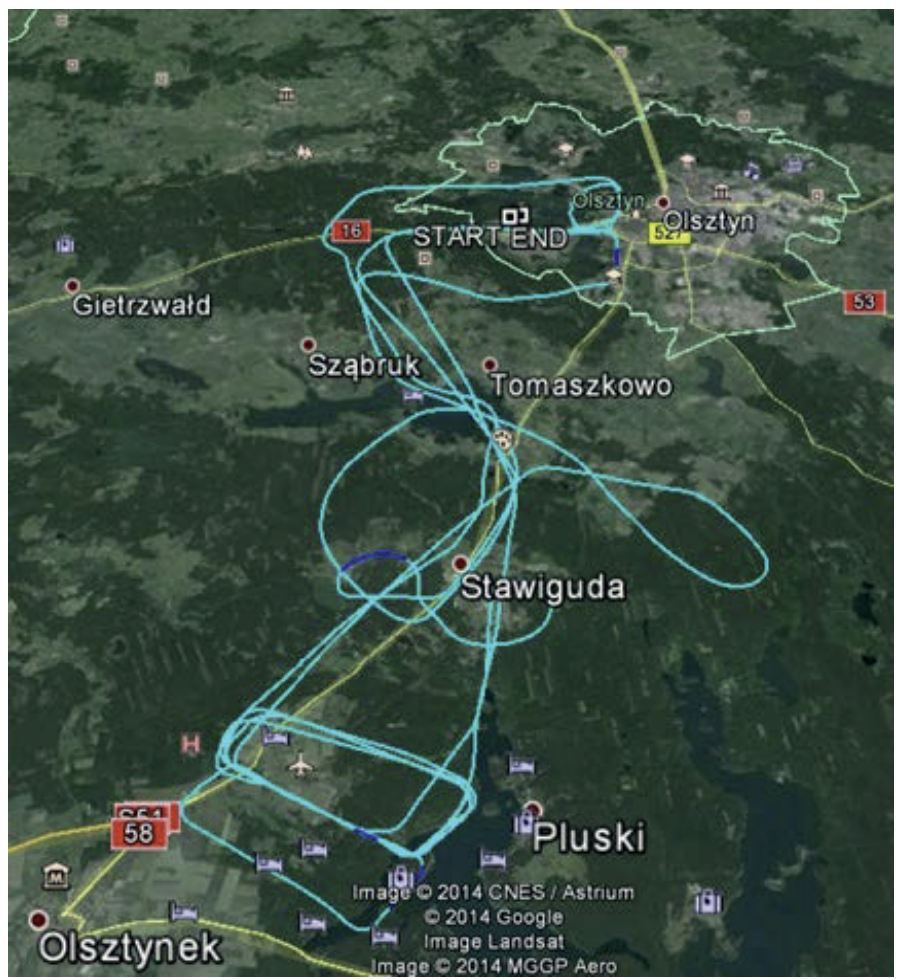

Fig. 2 The test route trajectory registered on Aug. 29, 2014

For every analysed epoch (1 second interval) real-time position using autonomous GPS and GPS/EGNOS data was determined. In the calculation algorithm "en-route" and PA variants were adopted. The differences in algorithms of these variants are: elevation mask ( $5^{\circ}$ for PA and $2^{\circ}$ for "en-route") and the maximum age of applied correction data according to Table 2. The values of HPL and VPL were determined on the basis of appropriate formulas: (1-14) for GPS/EGNOS and (15-17) for autonomous GPS solution.

Figures 3-8 present the results of research with parameters characterizing the accuracy and integrity of kinematic and static positioning.
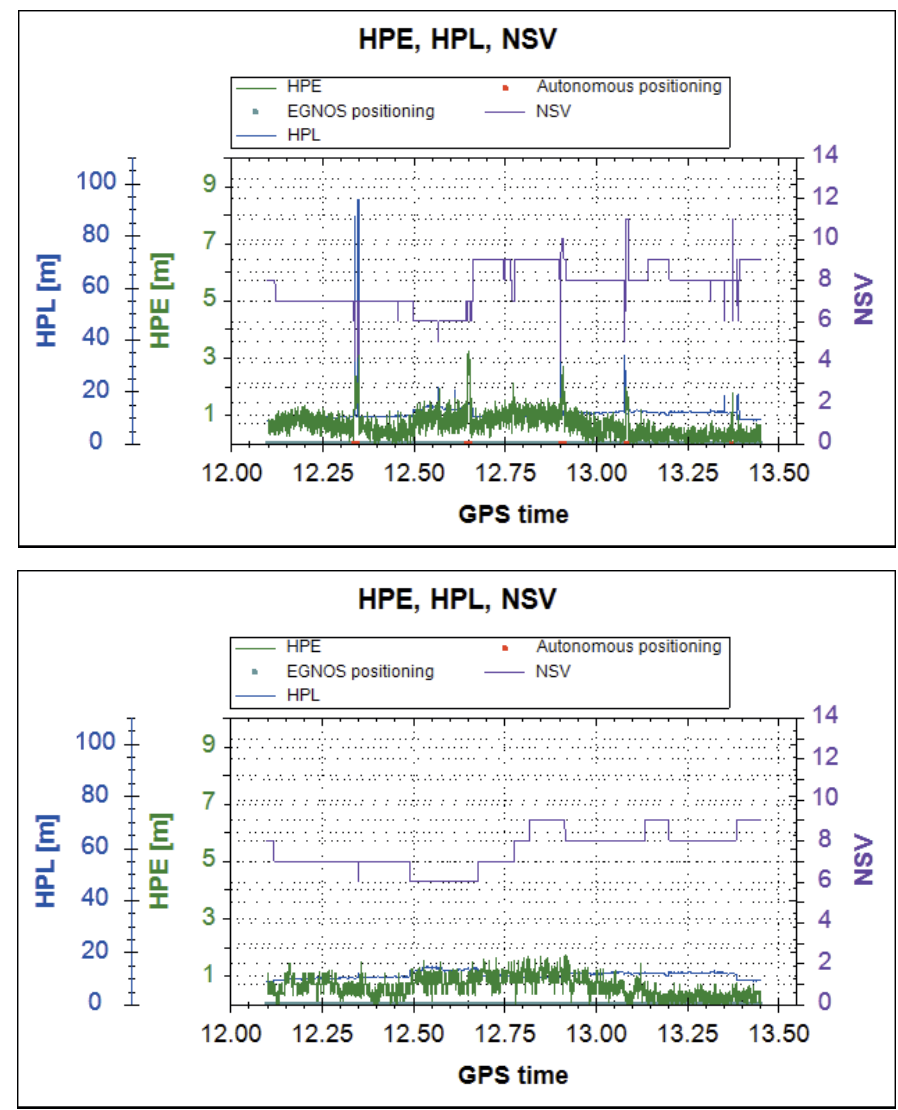

Fig. 3 The values of HPE, HPL and the number of satellites (NSV) used in "PA GPS/EGNOS" mode registered during the flight (up) and on EGNOS monitoring permanent station (down)
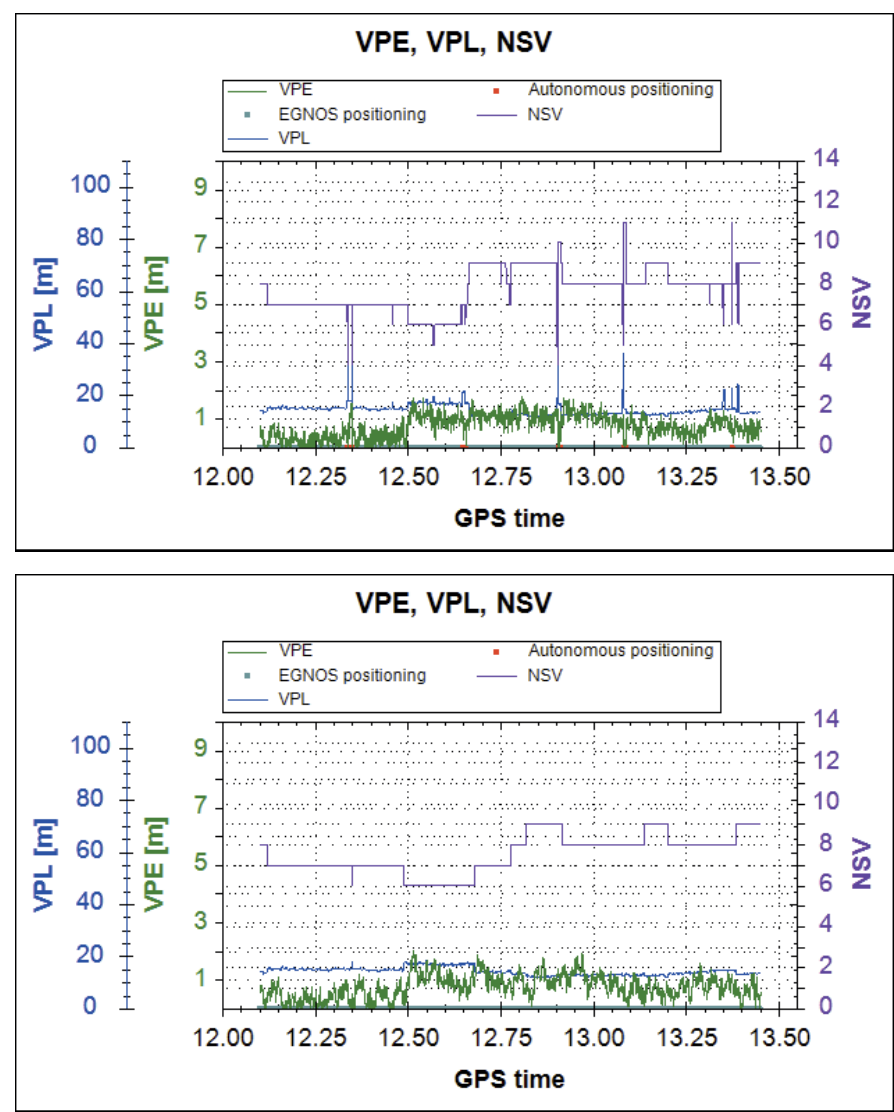

Fig. 4 The values of VPE, VPL and the number of satellites (NSV) used in "PA GPS/EGNOS" mode registered during the flight (up) and on EGNOS monitoring permanent station (down) 

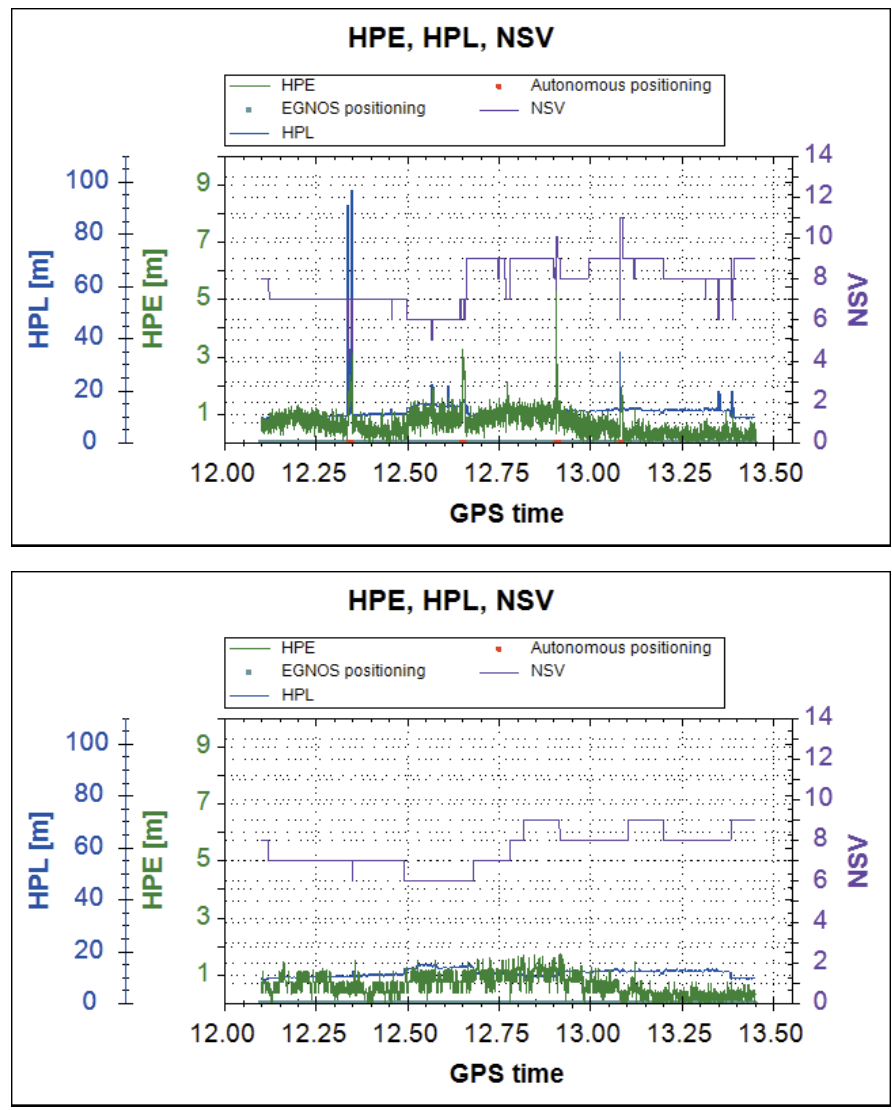

Fig. 5 The values of HPE, HPL and the number of satellites (NSV) used in "en-ruote GPS/EGNOS" mode registered during the flight (up) and on EGNOS monitoring permanent station (down)
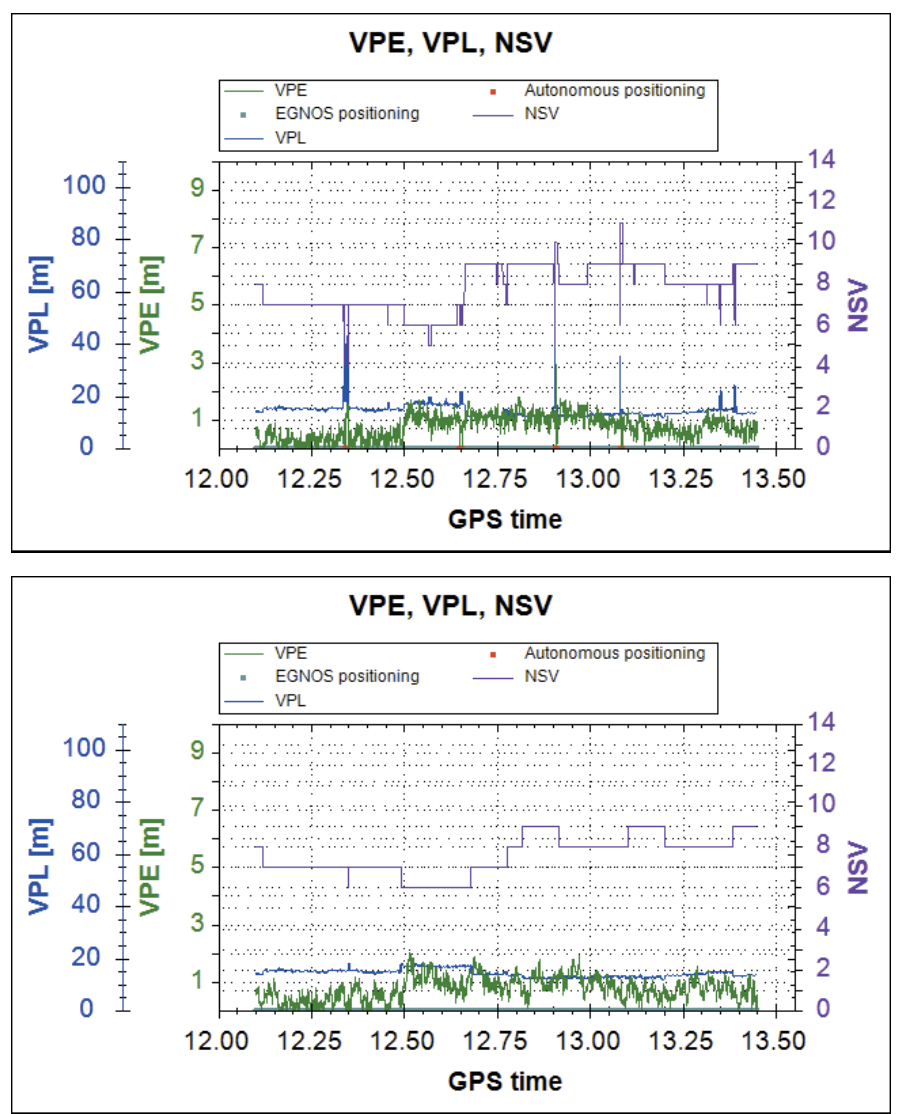

Fig. 6 The values of VPE, VPL and the number of satellites (NSV) used in "en-ruote GPS/EGNOS" mode registered during the flight (up) and on EGNOS monitoring permanent station (down)
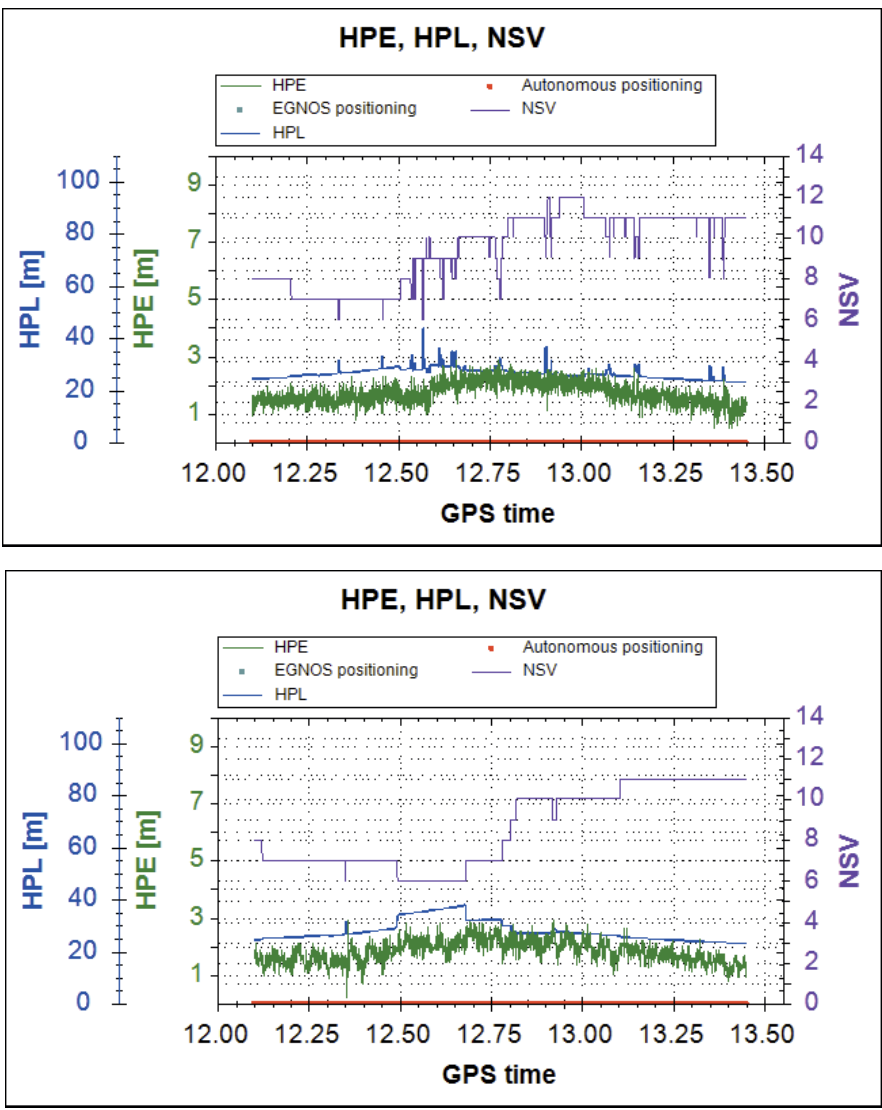

Fig. 7 The values of HPE, HPL and the number of satellites (NSV) used in "en-ruote autonomous" mode registered during the flight (up) and on EGNOS monitoring permanent station (down)
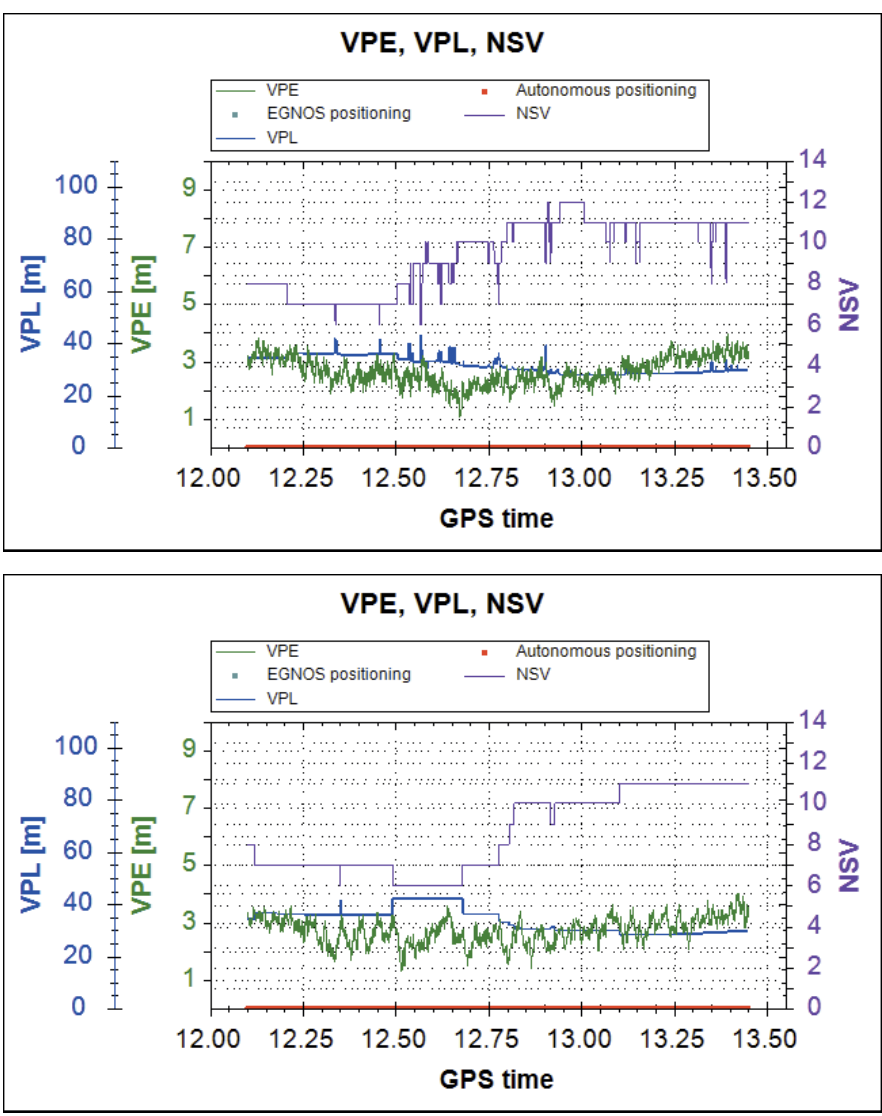

Fig. 8 The values of VPE, VPL and the number of satellites (NSV) used in "en-ruote autonomous" mode registered during the flight (up) and on EGNOS monitoring permanent station (down) 
In the figures 3-8 the impact of the kinematic motion of an aircraft (with a fairly high speed up to $150 \mathrm{~km} / \mathrm{h}$ ) on the values of the parameters characterizing the integrity of autonomous and GPS/EGNOS positioning and can be observed. The violent maneuvers of the airplane caused a change in positioning mode form GPS/EGNOS to standalone GPS (red colour in figures 3-6) which were not observed at static point. This was caused mainly by the decrease of the number of satellites (NSV) used in the navigation solution, which has a direct impact on the results of the analyses of HPE, VPE, as well as HPL and VPL. It can be clearly seen that GPS/EGNOS positioning (in en-route and PA variants) has improved accuracy (especially vertical) in correspondence with autonomous positioning. Overall assessment of the accuracy and integrity of positioning in the three studied variants is at the satisfactory level, not exceeding the levels defined by RTCA and ICAO regulations. Table 3 presents the numerical values of the obtained results.

Table 3 The results of accuracy and integrity analysis of autonomous GPS and GPS/EGNOS positioning during kinematic and static test at the OlsztynDajtki airport

\begin{tabular}{|c|c|c|c|c|c|c|c|}
\hline & $\begin{array}{l}\text { Type of } \\
\text { examined } \\
\text { data }\end{array}$ & $\begin{array}{c}\text { PA GPS/ } \\
\text { EGNOS } \\
\text { (flight) }\end{array}$ & $\begin{array}{c}\text { PA GPS/ } \\
\text { EGNOS } \\
\text { (static) }\end{array}$ & $\begin{array}{l}\text { en-route } \\
\text { GPS/ } \\
\text { EGNOS } \\
\text { (flight) }\end{array}$ & $\begin{array}{c}\text { en-route } \\
\text { GPS/ } \\
\text { EGNOS } \\
\text { (static) }\end{array}$ & $\begin{array}{c}\text { en-route } \\
\text { auton- } \\
\text { omous } \\
\text { (flight) }\end{array}$ & $\begin{array}{c}\text { en-route } \\
\text { auton- } \\
\text { omous } \\
\text { (static) }\end{array}$ \\
\hline \multirow{7}{*}{ 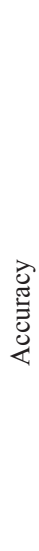 } & $\begin{array}{c}\mathrm{HPE}_{\text {mean }} \\
{[\mathrm{m}]}\end{array}$ & 0.67 & 0.65 & 0.66 & 0.65 & 1.74 & 1.85 \\
\hline & $\begin{array}{c}\mathrm{VPE}_{\text {mean }} \\
{[\mathrm{m}]}\end{array}$ & 0.77 & 0.77 & 0.77 & 0.77 & 2.67 & 2.74 \\
\hline & $\begin{array}{c}\mathrm{HPE}_{\mathrm{RMS}} \\
{[\mathrm{m}]}\end{array}$ & 0.78 & 0.74 & 0.78 & 0.74 & 1.78 & 1.89 \\
\hline & $\begin{array}{c}\mathrm{VPE}_{\mathrm{RMS}} \\
{[\mathrm{m}]}\end{array}$ & 0.86 & 0.87 & 0.87 & 0.87 & 2.71 & 2.77 \\
\hline & $\begin{array}{c}\mathrm{HPE}_{\max } \\
{[\mathrm{m}]}\end{array}$ & 3.24 & 1.76 & 5.32 & 1.76 & 2.90 & 2.94 \\
\hline & $\begin{array}{c}\mathrm{VPE}_{\max } \\
{[\mathrm{m}]}\end{array}$ & 1.80 & 2.06 & 2.95 & 2.06 & 4.00 & 4.04 \\
\hline & $\begin{array}{c}\mathrm{HPE}_{\text {st.dev. }} \\
{[\mathrm{m}]}\end{array}$ & 0.41 & 0.35 & 0.41 & 0.35 & 0.38 & 0.39 \\
\hline \multirow{9}{*}{ 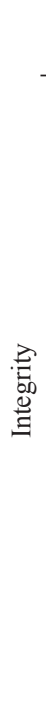 } & $\begin{array}{l}\mathrm{VPE}_{\text {st.dev. }} \\
{[\mathrm{m}]}\end{array}$ & 0.40 & 0.40 & 0.40 & 0.40 & 0.48 & 0.45 \\
\hline & $\begin{array}{c}\mathrm{HPL}_{\text {min }} \\
{[\mathrm{m}]}\end{array}$ & 8.76 & 8.77 & 8.92 & 9.03 & 23.09 & 23.10 \\
\hline & $\begin{array}{c}\mathrm{VPL}_{\min } \\
{[\mathrm{m}]}\end{array}$ & 11.76 & 11.80 & 12.22 & 11.80 & 27.80 & 28.20 \\
\hline & $\begin{array}{c}\mathrm{HPL}_{\max } \\
{[\mathrm{m}]}\end{array}$ & 95.21 & 15.41 & 97.67 & 15.07 & 45.27 & 39.68 \\
\hline & $\begin{array}{c}\mathrm{VPL}_{\max } \\
{[\mathrm{m}]}\end{array}$ & 44.97 & 18.55 & 44.74 & 16.62 & 41.14 & 44.43 \\
\hline & $\begin{array}{c}\mathrm{HPL}_{\text {mean }} \\
{[\mathrm{m}]}\end{array}$ & 11.37 & 11.27 & 11.35 & 11.61 & 26.53 & 27.87 \\
\hline & $\begin{array}{c}\mathrm{VPL}_{\text {mean }} \\
{[\mathrm{m}]}\end{array}$ & 14.32 & 14.31 & 14.45 & 14.31 & 31.78 & 33.74 \\
\hline & $\begin{array}{l}\mathrm{HPL}_{\text {st.dev. }} \\
{[\mathrm{m}]}\end{array}$ & 2.72 & 1.32 & 2.79 & 1.36 & 2.22 & 3.90 \\
\hline & $\begin{array}{l}\mathrm{VPL}_{\text {st.dev. }} \\
{[\mathrm{m}]}\end{array}$ & 2.01 & 1.47 & 2.11 & 1.47 & 3.20 & 4.59 \\
\hline
\end{tabular}

Presented in the table 3 results show the maximum positioning errors in air traffic at: $\mathrm{HPE}_{\max }=5.32 \mathrm{~m}$ (in the case of "en-route GPS/EGNOS" flight) and VPE ${ }_{\max }=4.04 \mathrm{~m}$ (in the case of "en-route autonomous" static), which meets the accuracy requirements of the system to be used in aviation. In addition, the results obtained during the flight are not much worse than those obtained on static point. The discrepancies may result from a different geometry of satellites used in the kinematic and static positioning. The results obtained in the "PA GPS/ EGNOS" mode are similar to those obtained in the "en-route GPS/EGNOS" mode, which is due to the fact that the differences in the algorithms used for computation of these modes are not very significant. However, positioning using EGNOS have significantly better accuracy and integrity both horizontally and vertically with respect to the autonomous positioning. In general, integrity of positioning based on the values of PLs is at a level that meets the requirements of the NPA and APV-1 approach. However, it should be noted that maximum values of HPL and VPL for the kinematic modes "PA GPS/EGNOS" and "en-route GPS/EGNOS" reached: $\mathrm{HPL}_{\max }=95.21 \mathrm{~m}, \mathrm{VPL}_{\max }=44.97 \mathrm{~m}$ and $\mathrm{HPL}_{\text {max }}=97.67 \mathrm{~m}, \mathrm{VPL}_{\text {max }}=44.74 \mathrm{~m}$ respectively. In these cases, the violent maneuvers of the pilot going hand in hand with no perfect location of GNSS antenna, resulted in change of positioning mode from GPS/EGNOS to autonomous GPS and therefore the limit values of PL for APV procedures were exceeded.

\section{Conclusions}

The subject of the study was to examine current autonomous GPS and GPS/EGNOS integrity and accuracy for flight applications in north-eastern Poland. The practical experiment was performed on August 29, 2014 at the Olsztyn-Dajtki airport and its vicinity. The observation data were collected with two Septentrio receivers, one placed on board of Cessna plane and second working at static permanent EGNOS monitoring station. Data were analysed in two different modes: autonomous GPS and GPS/EGNOS, strictly according to ICAO and RTCA guidelines. Both modes were evaluated in en-route variant and additionally GPS/EGNOS mode was also examined in PA variant.

Presented results of examination of autonomous GPS and GPS/EGNOS performance in north-eastern Poland confirmed the accuracy and integrity of GPS/EGNOS positioning declared by EGNOS provider, which is crucial to aviation applications. However, few gaps in GPS/EGNOS positioning during the flight were observed, it must be stressed that they were due to violent manoeuvres of the plane and the temporary location of GNSS antenna - in the cockpit of the plane. The future practical experiments concerning the use of EGNOS in air transport are planned to be performed with dedicated aviation antenna placed on the fuselage of the plane.

Nevertheless, achieved results and analyses presented in the paper are very promising and the use of GNSS navigation in aviation in Europe seems to be inevitable in the near future. 


\section{References}

[1] Speidel, J., Tossaint, M., Wallner, S., Ávila-Rodríguez, J. Á. "Integrity for Aviation: Comparing Future Concepts.”. Inside GNSS, July/August 2013, pp. 54-64. www.insidegnss.com/node/3625

[2] Department of Defense, Department of Homeland Security, Department of Transportation "2014 Federal Radionavigation Plan." National Technical Information Service, 2015, Springfield, Virginia. http://www. navcen.uscg.gov/?pageName=pubsMain

[3] Radio Technical Committee for Aeronautics (RTCA) "Minimum Operational Performance Standards Global Positioning System/AircraftBased Augmentation System Airborne Equipment." Doc. DO-316, 2009, Washington, DC. http://www.rtca.org

[4] Radio Technical Committee for Aeronautics (RTCA) "Minimum Operational Performance Standards for Airborne Equipment Using Global Positioning System/Wide Area Augmentation System.” Doc. DO-229D. 2006, with Change 1, 2013, Washington, DC. http://www.rtca.org

[5] Radio Technical Committee for Aeronautics (RTCA) "Minimum Operational Performance Standards for GPS Local Area Augmentation System Airborne Equipment.” Doc. DO-253C, 2008, Washington, DC. http://www.rtca.org

[6] Grunwald, G., Bakuła, M., Ciećko, A. "Study of EGNOS accuracy and integrity in eastern Poland.”. The Aeronautical Journal, 120(1236), pp. 2016. https://doi.org/10.1017/aer.2016.66

[7] International Civil Aviation Organization (ICAO) "Global Air Navigation Plan for CNS/ATM Systems”, 2nd Edition, Doc 9750 AN/963, 2002. www.icao.int/publications/Documents/9750_2ed_en.pdf

[8] International Civil Aviation Organization (ICAO) "International Standards and Recommended Practices (SARPS) - Annex 10 to the Convention on International Civil Aviation - Aeronautical Telecommunications - Volume I, Radio Navigation Aids", 6th Edition, 2006. http://www. theairlinepilots.com/forumarchive/quickref/icao/annex10.1.pdf
[9] Navipedia, European Space Agency (ESA), 2016. http://www.navipedia. net/index.php/Integrity

[10] Rakipi, A., Kamo, B., Cakaj, S., Kolici, V., Lala, A., Shinko, I. „Integrity Monitoring in Navigation Systems: Fault Detection and Exclusion RAIM Algorithm Implementation.”. Journal of Computer and Communications, 3, pp. 25-33. 2015. https://doi.org/10.4236/jcc.2015.36004

[11] International Civil Aviation Organization (ICAO) "Global Navigation Satellite System (GNSS) Manual”, 1st Edition, Doc 9849 AN/457, 2005. http://www.icao.int/Meetings/PBN-Symposium/Documents/9849_ cons_en[1].pdf

[12] Centre National d'EtudesSpatiales (CNES), European Commission (EC), European Space Agency (ESA) "User Guide for EGNOS Application Developers.” ED 2.0, 15/12/2011. https://egnos-user-support.esspsas.eu/

[13] Tiberius, C., Odijk, D. "Does the HPL bound the HPE?". NAVITEC. In: Proceedings of NaviTec'08 workshop, 2008, ESA-Estec, Noordwijk, The Netherlands. 2008.

[14] Felski, A., Nowak, A., Woźniak, T. "Accuracy and availability of EGNOS: results of observations". Artificial Satellites, 46(3), pp. 111-118. 2011. https://doi.org/10.2478/v10018-012-0003-0

[15] Popielarczyk, D., Templin, T., Łopata, M. "Using the geodetic and hydroacoustic measurements to investigate the bathymetric and morphometric parameters of Lake Hańcza (Poland).” Open Geosciences, 7, pp. 854-869. 2015. https://doi.org/10.1515/geo-2015-0067

[16] Grunwald, G., Bakuła, M., Ciećko, A., Kaźmierczak, R. "Examination of GPS/EGNOS integrity in north-eastern Poland.”. IET Radar, Sonar \& Navigation, 10(1), pp. 114-121. 2018. https://doi.org/10.1049/iet-rsn. 2015.0053 